\title{
Experiential Learning in Second-Language Classrooms
}

Sonja Knutson

This article is a discussion of some of the issues surrounding experiential learning in the second-language classroom. Experiential learning is defined by the inclusion of phases of reflection designed to help the learner relate a current learning experience to past and future experience. The author seeks to establish a theoretical foundation for incorporating experiential phases into the second-language classroom by exploring past methods of teaching English as a second language, as well as looking at research in the field of second-language acquisition in the light of experiential methodology. The implications of experiential learning to second-language acquisition, in particular the aspects of motivation and investment, are explored, and some pitfalls of the experiential curriculum and their possible solutions are discussed. Finally, some possible projects adaptable to experiential methods are outlined, and areas needing further research, especially in the area of student voice and empowerment, are proposed.

Cet article est une discussion de quelques questions portant sur l'apprentissage par l'expérience dans une salle de classe de langue seconde. L'apprentissage par l'expérience implique l'inclusion d'étapes de réflexion conçues pour aider l'apprenant à faire le lien entre son apprentissage en cours et ses expériences antérieures ou à l'avenir. En étudiant des méthodes employées par le passé pour enseigner $l^{\prime}$ ALS et en revoyant la recherche en acquisition de langue seconde à la lumière de la méthodologie expérientielle, l'auteure veut établir une base théorique pour l'intégration d'étapes expérientielles dans l'enseignement en langue seconde. Les incidences de l'apprentissage par l'expérience sur l'acquisition de la langue seconde, notamment sur la motivation et l'engagement, sont présentées. L'auteure évoque les pièges dans un programme d'études basé sur l'apprentissage par l'expérience et présente des stratégies pour les éviter. En dernier lieu, l'auteure décrit des propositions de projets pouvant s'adapter aux méthodes expérientielles et suggère des pistes de recherche, notamment dans le domaine de l'habilitation des élèves.

I hear and I forget, I see and I remember, I do and I understand. (Confucius)

From the time of the first teachers, it has been recognized that an important relationship exists between experience and learning. Expressions such as "experience is the best teacher" and the "school of life" demonstrate our 
Western world's respect for the role of experience in learning. Yet as old as the experiential approach to learning is, the transformative process from experience to learning is not clearly understood. If experience is one of the cornerstones of learning, the question faced by educators is this: What is it about experience that leads to learning? Kolb (1984) tackled this question in his work entitled Experiential Learning: Experience as the Source of Learning and Development. He created a now widely accepted model of the learning cycle to demonstrate the process by which experience could be translated into learning. In order to learn, one must go through a series of steps after an initial experience: There must be a reflection on the experience followed by an understanding of what the new learning means to the individual and a conceptualization of how it can be used in the future.

The assumption is that we seldom learn from experience unless we assess the experience, assigning our own meaning in terms of our own goals, aims, ambitions and expectations. From these processes come the insights, the discoveries, and understanding. The pieces fall into place, and the experience takes on added meaning in relation to other experiences. (Saddington, 2001, p. 1)

Experience per se is, therefore, only the first step in the learning process, and for learning to be drawn from it, the experience must be followed by the vital step of reflection. The ability to reflect on an experience, and on initial reactions to the experience, is the "missing link" that defines the relationship between experience and learning.

Experiential learning as a philosophy is based on the ideals of active and reflective learning, building on previous learning experiences and requiring the personal involvement of the learner. In the field of second-language acquisition (SLA), the experiential approach encourages learners to develop the target language skills through the experience of working together on a specific task, rather than only examining discrete elements of the target language. The reflection phase requires learners to engage actively with their own past acquisition experiences and focuses them on the future. Experiential methodology holds many potential benefits for SLA in terms of motivation, investment, and cultural understanding.

\section{Experiential Philosophy in the Classroom}

Experiential learning has been applied to a wide variety of learning situations, from business team-building seminars, to orienteering, to math and science classes. The method is easily adaptable to a wide variety of educational settings, especially to classrooms where project-based and task-based learning already form the core of the curriculum. All classroom activities form a part of student experience. An activity can be done in a group or individually and successfully mined for affective value through questioning 
techniques and student reflection. The division of the learning process into experiential phases helps sequence the learning activities toward the achievement of the desired learning outcomes.

Experiential learning challenges all learner domains holistically, rather than fragmenting the learning process into cognitive, affective, and psychomotor skill acquisition. Rogers (1969), a staunch proponent of experiential learning, describes this basic philosophy:

It has a quality of personal involvement-the whole person in both his feeling and cognitive aspects being in the learning event. It is self-initiated. Even when the impetus or stimulus comes from the outside, the sense of discovery, of reaching out, of grasping and comprehending, comes from within. It is pervasive. It makes a difference in the behavior, the attitudes, perhaps even the personality of the learner. (p. 5)

Experiential learning encourages personal input, initiative, and self-direction in the learning process. Activities begin with accessing the specific past experiences of students, and then building on these experiences to construct a framework for learning unique to the requirements and learning style of each student. In practice, experience-based, project-based, and task-based learning become experiential when elements of reflection, support, and transfer are added to the basic experience, transforming a simple activity into an opportunity for learning. Koenderman (2000) provides an experiential model based on these elements, a series of phases that outline the sequencing of classroom activities from the introduction of a topic or theme to the conclusion. In the exposure phase a topic is introduced, and students are given the opportunity to reflect on their own experiences in this area and to relate the topic to their personal learning goals; in the participation phase the students become personally involved as they participate in an activity, either in the classroom or outside, intended to build on or enhance their previous experience; in the internalization phase a debriefing exercise is initiated by the teacher, and the students have the opportunity to reflect on their participation in the activity and discuss potential effects on their future behavior or attitudes; and finally, in the dissemination or transfer phase the students apply and present their learning, linking it with the world outside the classroom.

The philosophical concepts of experiential learning can provide the basis for all instructional practices, including the creation of the learning environment, the setting of objectives, the choice of projects, the sequencing of activities, and the assessment of learners. The facilitator can debrief each day's activities, or debrief only at the conclusion of the project. Groups can work through all the experiential phases during a 10-minute activity or during a five-week course: The phases remain the same despite the length or complexity of the activity. 
Experiential learning is accepted and even promoted in the field of education, as educators have "finally begun to recognize the complexity of the educational process" (Hendricks, 1994, p. 1). However, despite acknowledged benefits, experiential methods are still far from being universally accepted by educators themselves. There are several reasons for this, including classroom time constraints, difficulties with assessment, and lack of training in how to meet course outcomes experientially.

Experiential learning requires teachers to take time to encourage reflection. This is not only time-consuming, but requires the creation of a comfortable, relaxed classroom atmosphere and skillful questioning on the part of the facilitator. The results of taking the time required for periods of reflection is not something that can be measured quantitatively. Although "educators ... are giving up the idea that they can dissect, predict, and control learning with technological precision" (Hendricks, 1994, p. 1), and although there has been some movement toward more qualitative assessment in certain educational domains, many teachers are still expected to "teach to a test" (Hussin, Nooreiny, \& D'Cruz, 2000, p. 1). When time is constrained, administrative support limited, and course outcomes primarily focused in the behavioral domain, teachers find it difficult to try to incorporate experiential teaching methods even if they believe in their value.

Experiential learning also requires teachers to take on a different role in the classroom than the traditional teacher-as-expert. In the classroom they become facilitators, guides, and helpers (Spruck-Wrigley, 1998). Many ESL instructors are already accustomed to this role. However, it often requires a paradigm shift for educators whose training and experiences have been to teach subject content using a teacher-centered approach (Brooks-Harris \& Stock-Ward, 1999). Suzanne Roy, a pedagogical consultant for a large school board in Montreal, has done inservice work with teachers to implement experiential learning and portfolio assessment across the subject spectrum. Some of the resistance she runs into includes a perception of projects as frivolous, unrelated to the meat of subject content, and uncontrollable (personal communication, October 16, 2000). However, experiential learning is not uncontrolled; on the contrary, to be successful it requires the teacher to be prepared and organized before a project begins. The teacher must think through each phase, planning with potential difficulties in mind, yet being creatively open to "teachable moments" (Spruck-Wrigley, 1998). A venue needs to be created for students to share their reflections and feelings about their experiences, both positive and negative, in a nonjudgmental and open environment. In true experiential learning, the teacher-as-facilitator role is central, and the project will succeed "if the teacher can provide the necessary guidance through skillful, astute questions and a receptive, accepting heart and mind" (Janeway, 1977, p. 7). Students are thus provided with a structure 
by which they can analyze their experience and given the tools to transform it into learning.

\section{Experiential Techniques in the Teaching of English as a Second Language}

Methods of facilitating SLA have evolved over the years due to influences and developments in the fields of linguistics, education, and cognitive and social psychology (Brown-Mitchell \& Ellingson-Vidal, 2001). The teaching practices currently being taught to future ESL practitioners reflect the current educational trend toward cooperative and collaborative learning (Wilhelm, 1999). As ESL methods developed through the years, "each new method broke from the old, but took with it some of the positive aspects of previous practices" (Brown, 1987, p. 52). ESL classes today are set up differently from traditional grammar-translation classes. Language use and language-learning are social activities.

They occur best in situations which encourage negotiation of meaning and learner collaboration with other learners. Language learning necessarily involves active participation through taking risks, testing hypotheses, making plans and decisions, and making judgements about one's own progress. (Wilhelm, 1999)

When these approaches are implemented, students learn to help themselves learn, ask for help from each other and from the teacher, learn language by using it in real settings, explain what they are learning and how they are learning, and grade themselves as a way to measure their strengths and weaknesses (Wilhelm, 1999). Through collaboration on a project, students use and manipulate language in a natural language environment.

Experiential learning in the ESL classroom builds on the principle that language-learning is facilitated when students are cooperatively involved in working on a project or task, and when the project includes the phases of exposure, participation, internalization, and dissemination. Projects that are challenging, communicative, and meaningful, and that provide opportunities for student ownership and participation in their own language-learning, create an environment conducive to sustaining motivation to learn the target language (Brown, 1987; Hussin et al., 2000). By looking more closely at the individual phases of experiential learning in the light of some past methods and research into SLA, a theoretical foundation for incorporating experiential phases into ESL classrooms can be established.

Exposure phase. Beginning with a creatively presented exposure phase, students are initiated into the project in a manner that will activate background schema, past experiences, and previous knowledge about the subject of the project. This activation of background knowledge before launching an activity is not unique to the field of ESL; teachers have long been aware of the 
value of this type of activity. Schema theory recognizes that each student brings "information, knowledge, emotion, experience, and culture" to each classroom activity (Brown, 1987, p. 284). Accessing background knowledge before launching an activity helps enrich the learning experience by preparing the groundwork for new experiences to build on top of old ones. The exposure phase of experiential learning offers explicit and effective techniques for activating schemata. These techniques include an opportunity for students to understand the objectives of the activity and set goals for themselves. The teacher can then direct the class through the use questions to encourage reflection on past experiences with the topic or activity. A wellstructured exposure phase also clearly lays out for students the pedagogical purpose and rationale for the project, and can lead to greater learner awareness of, and involvement in, their own learning process (Nunan, 1995).

Participation phase. The participation phase of experiential learning is the actual activity or experience. Because it is project-based, the communicativeexperiential syllabus uses a collaborative, holistic approach to languagelearning, which again is not unique to the field of ESL. Vygotsky's (1978) theory of the zone of proximal development (ZPD) refers to the gap between the students' current ability and their potential ability with peer or mentor guidance. This theory provides strong support for the inclusion of cooperative learning strategies in SLA (Doolittle, 1995). Research into applications of Vygotsky's theory in SLA contexts has shown that learner-learner interaction is indeed beneficial to ESL learners (Kolb, Kowal, \& Swain, 1994; Wajnryb, 1990). Since the early 1980s, second-language teachers have been deluged with research into SLA that supports the communicative approach to language-learning (Brown, 1987). However, the contradictory ways in which communicative teaching is viewed have led to some confusion. Some educators see it as teaching "how to communicate" and focus on the teaching of explicit grammar forms and formulaic discourse; others understand communicative teaching as involving the learner as a participant in classroom communication and do not focus on explicit language forms (Stern, 1990). The term communicative-experiential syllabus was coined by Tremblay, Duplantie, and Huot (1990) to define and distinguish a syllabus, based on both experiential learning and communicative theory, in which the focus is on the linguistic interaction that occurs between learners as they work on a project. The communicative and integrated aspects of experiential learning are supported by research into the advantages of a holistic approach to SLA (Crandall \& Pharness, 1991; Freeman \& Freeman, 1988; Rigg, 1991).

Internalization phase. The internalization phase of a communicative-experiential syllabus is accomplished through skillful questioning on the part of the facilitator to help draw learners' attention to their own feelings and participation in the language-learning experience. This reflection on the experience seeks to involve the emotions and identity of the learner. The 
philosophy of experiential learning as it relates to SLA can also be seen in some of the innovative, yet now rarely employed, ESL methods of the 1970s. Although these methods have been overlooked by many mainstream ESL practitioners, they were based on some important research in language acquisition theory and psychology (Brown, 1987). The Silent Way, developed by Gattegno (1972), promoted the ideal that learners should take responsibility for their own language acquisition and should be taught not only information about the language, but also how to learn a language. In his method, similar to the role of a facilitator in an experiential classroom, the teacher plays a background role, allowing students time to try to work out answers on their own. During the debriefing phase of experiential projects, students are questioned about their own language-learning and how they feel it progressed, as well as how they feel they contributed to their own progress. Although the teacher sets up the questions, no answers are provided, and the teacher responds in a nonjudgmental way to any and all students' contributions. Community Language Learning (CLL), developed from work by Curran (1972), was based on the notion that language, being a social activity, should develop in a supportive social context. "CLL is an attempt to put Carl Roger's philosophy into action and overcome some of the threatening affective factors in second language learning" (Brown, 1987, p. 60). CLL has clear links to experiential philosophy; its belief in the positive power of group dynamics, especially in the debriefing phase, is also a component of experiential learning. Suggestopedia, developed by Lozanov (1978), introduced the idea that students should be relaxed and open to experiencing the language, even to the point of taking on a new identity as a successful language-learner. The Silent Way, CLL, and Suggestopedia were founded on learner-centeredness, self-discovery, reflection, social interaction, and positive self-concept. These principles are central to experiential learning and reinforced during the internalization phase.

Dissemination phase. The importance of the final phase of experiential methodology, linking the classroom learning with the real world outside the classroom, came to the forefront of developments in ESL with the NotionalFunctional syllabus (Brown, 1987). ESL researchers and practitioners came to recognize the need for language-learners to be able to transfer their classroom experiences into their day-to-day contexts. The Canadian Language Benchmarks (Citizenship and Immigration Canada, 1996), a federally developed framework for assessing communicative and performance levels of newly arrived ESL students enrolled in federally funded programs, recognized a national need for real-life competences. Instead of basing proficiency levels on knowledge of grammatical forms, proficiency is now based on notional-functional tasks founded in real-life situations. Teachers in these programs are encouraged to make a clear link between the classroom and the world outside. These tasks are experiential by nature, and transfer may occur 
in genuine ways. Projects may culminate in a role-play of a social situation in class or in students going on a field trip to practice newly acquired skills. This type of specific transfer is received positively by students, who feel that their practical language needs are thus successfully being met (Nunan, 1995). Metaphoric transfer can also be used effectively, if links are clearly made between the class activity and its real-life parallel. For example, students could be asked to explain how they think that group work and the responsibility to take on leadership roles might help them on the job. Thus the dissemination phase, the conclusion of an experiential activity, provides the student with a clear link to his or her real needs and goals and can be highly beneficial and motivational.

\section{The Communicative-Experiential Syllabus}

Unlike the study of many academic subjects, the study of English as a second or foreign language is undertaken primarily for the purpose of communication to a wider audience. English-language skills are gained specifically as a medium of communicating other types of knowledge, perhaps academic or business-related, or perhaps simply for social conversation. People rarely take ESL classes out of simple interest in the workings and mechanics of the language; their intent is to reach a particular goal. The mastery of the language is the often frustrating barrier that prevents them from reaching social, career-related, or scholastic goals. A significant benefit of experiential learning lies in the investment that learners make toward their particular project. Motivation is of critical importance in SLA for a variety of reasons.

Motivation contributes not only to the success of students studying another language, but also influences their level of interaction with native speakers and whether they will seek opportunities to practice the language outside of class and long after formal language study is over (Ely, 1986; Gardner \& MacIntyre, 1991; Oxford \& Scarcella, 1992). Oxford and Shearin (1996) point out that "motivation determines the extent of active, personal involvement in foreign or second learning. Conversely, unmotivated students are insufficiently involved and therefore unable to develop their potential L2 skills" (p. 121). A frequent observation of students involved in projects is that they work harder and spend more out-of-class time on the project and speaking in English than they ever had before (Parks, 2000; personal communication, August 6, 2000). Although some students may resist any type of group work, teachers find that most students involved in a project will invest a great deal of time, effort, and energy into the completion of their project, which is generally a formal or public presentation of the finished product (Padgett, 1994; Parks, 2000; Spruck-Wrigley, 1998).

Another valuable component of experiential learning linked to investment is its contribution to the learner's positive self-perception and increased confidence with the target language (Parks, 2000; Spruck-Wrigley, 1998). 
Although projects are in general more time-consuming than traditional classroom demands, teachers frequently observe that students' ownership and control over their project can lead to a sense of empowerment and to a positive perception of themselves as successful language-learners, in contrast to more formal written and oral evaluations, which often have the opposite effect (Parks, 2000; Karsenti, 2001). When students do not invest in tasks that involve oral production of the target language, it may be because they fear failure and public embarrassment. A carefully initiated experiential project can produce a positive experience in oral production tasks. The facilitator can thus encourage in a learner an "anticipation of success" (Parks, 2000, p. 82), which can provide a positive medium for the language-learner to participate in speaking tasks.

Although the main goal of task-based learning is the authentic language produced as a result of group work, other competences can be acquired, seemingly incidentally, as a result of the skillful facilitation of this method. Experiential learning not only provides students with plenty of communicative opportunities in the target language, but also allows students a forum to access a wide variety of new skills unrelated to the actual language-learning. These include the practical skills needed for the completion of the project (e.g., videotaping, making a poster, conducting an interview, using PowerPoint.), to cognitive and employability skills (critical reflection, self-evaluation, teamwork, and leadership). These skills are learned and practiced throughout the project and can be of great benefit to the general education of the whole individual.

\section{Overcoming Pitfalls in Experiential ESL}

Stern (1990), one of the first proponents of experiential learning in the teaching of second languages, points out the existence of potential trouble spots in teaching experientially. One of main pitfalls he notes is the potential for the project to be more linguistically demanding than the level the students can manage. This flies in the face of Krashen's (1985) $i+1$ model. Krashen advises that students should be exposed to language that is a little above their current level of proficiency. Expecting students to function at a much higher level than their proficiency level will only induce frustration and a tendency to lapse into their mother tongue, as indeed can be occasionally observed during the running of a project.

A continual difficulty with any type of group work in ESL classes is mother tongue use. Students working alone on a project, especially outside of class, will be strongly tempted to slip into their native language when no longer under teacher supervision. One way to counteract this difficulty is to hold a reflective-type class session near the beginning of the term. Asking groups to discuss questions like "What do you feel is your own role in contributing to the successful language-learning of the other students in your 
group?" or "How do you feel when you try to speak English and others switch to your native language-do you continue in English or do you switch to your mother tongue as well? Why do you think you respond this way?" Students need to be aware that they share the responsibility not only for their own learning, but for the learning of the other students in the class as well.

When a student dislikes group work, it can be a major difficulty for teachers who are trying to incorporate any type of communicative approach in the classroom. Students who have been in school systems that value individual work exclusively may suffer a type of "culture shock" when exposed to the concept of teamwork and group work so prevalent in North American school culture (Parks, 2000). Unfortunately for students who resist collaborative work, there are few classroom situations, and few professions, in which the ability to function cooperatively in a team is completely unnecessary. The advantage of experiential learning is that, through pre- and post-reflection on questions about working in a group, these students can explore their resistance to group work. Skillful debriefing by the facilitator should encourage all students to discuss their frustrations with team work, why they choose the roles that they take on in a particular group, and what positive or negative past experiences they bring to their group work. The self-awareness that can grow from these discussions may be important to the students' futures not only in social and classroom use of the target language, but to their future careers as postsecondary students or employees.

One of the thorniest issues that proponents of experiential philosophy face is the issue of assessment. This is further complicated by the fact that students who are taking ESL for the purpose of furthering their academic or business careers must pass some type of English proficiency exam. Preparing for these exams requires students to focus on their competence with various forms and functions of the language. Experiential philosophy proposes that learners set their own goals and assess themselves (Rogers, 1969). For students who are trying to reach a certain standardized level of language skills, self-evaluation is not always helpful; these students need to know that their English is accurate enough to pass the exam. Experiential projects do, however, lend themselves well to rubric-style evaluation of employability skills like teamwork and leadership and language skills, especially oral proficiency (Lewis, Moss, \& Van Duzer, 1998). Experiential learning assessment relies primarily on formative assessment and is often accomplished through a combination of self, peer, and teacher evaluation techniques collected in portfolio format, along with any graded tests or papers, for a summative evaluation (Padgett, 1994).

In deciding whether to incorporate experiential techniques into the classroom, especially into an ESL class that concludes in a standardized test, teachers need to remember that it is not a case of "all or nothing." Stern (1990) 
advocates what many educators already do: See the two philosophies as complementary and develop a curriculum that incorporates both approaches. A comprehensive curriculum may be especially important when working with adult learners, who often prefer explicit teaching and who may initially resist or devalue group work (Spruck-Wrigley, 1998).

I have incorporated experiential teaching into intensive preuniversity projects through careful selection of activities that are easily adapted experientially like oral presentations and projects that make use of technology. These experiential activities alternate with, and complement, more formfocused and teacher-centered learning experiences. North American universities expect a great deal of team and group work, as well as a high level of familiarity with technology, so experiential-type activities like creating a Power-Point presentation help ESL students to acquire important universitysuccess skills. Although these skills will not be tested on an entrance exam, they are enormously valuable to a student's ability to adapt to North American university classroom expectations.

\section{Potential of Experiential ESL}

The potential themes for project-based learning are endless and can be adapted to any level: from literacy ESL to preuniversity academic ESL. Teachers can adapt projects to suit the individual needs and interests of their particular students, and by sequencing the activities through the phases of experiential learning teachers can help ensure that the activities result in an optimal environment for learning. ESL teachers have used many types of projects: from debates, to video projects, to computer technology-based products. Projects can be adapted to any level and any age of ESL learners. Children can be involved in writing and illustrating their own versions of classic fairy tales for display. In high school classes, drama or video projects can help adolescents to feel more comfortable with oral production tasks and to learn teamwork skills. Adult ESL students can participate in communitybased projects or form job or book clubs to assist each other with social and cultural information. Advanced students can work in small teams to design, research, and present lessons on important issues dealing with everything from coping in the new culture to writing a research paper. Universitybound international students in programs oriented to academic ESL can create class Web pages and Power-Point presentations on their field of study.

The implications of experiential learning are profound for the field of SLA. It is rare that a language-learner learns in isolation; on the contrary, language use is social, requiring learners to adapt not only to a new code for expressing themselves, but also to become aware of new and different cultural expectations, social norms, and practices (Wallerstein, 1983). Research into the social construction of language, social identity of the languagelearner, and theories of investment and motivation need to be further ex- 
plored in the context of experiential learning. Experiential learning, with its emphasis on critical self-reflection, may prove to be a beneficial approach for helping learners to negotiate social meaning and their own shifting identities in a new culture. Other aspects of experiential ESL curriculum that need to be studied include: the effect of creating a product for a wider audience; the choosing of team roles and organizing of team work; the benefits arising from having a voice and a forum in which to express opinions and ideas; and the empowerment that arises from just simply hearing one's own voice expressing ideas in a social context in another language.

Teaching practices derived from experiential philosophy have the potential to give public voice to those who have been marginalized, to empower those who are fearful or shy, and to increase learners' ownership and responsibility for their own learning (Wallerstein, 1983). Practitioners currently involved in teaching ESL can make use of its potential to help students negotiate far more than just the linguistic code. Through adapting experiential learning methods to current ESL teaching situations, teachers can help learners to form positive identities of themselves as successful languagelearners and thus perhaps ease the often frustrating task of learning a new language.

\section{References}

Brooks-Harris, J.E., \& Stock-Ward, S.R. (1999). Workshops: Designing and facilitating experiential learning. Thousand Oaks, CA: Sage.

Brown, H.D. (1987). Principles of language learning and teaching. Englewood Cliffs, NJ: Prentice-Hall.

Brown-Mitchell, C., \& Ellingson-Vidal K. (2001). Weighing the ways of the flow: Twentieth century language instruction. Modern Language Journal, 85, 26-36.

Citizenship and Immigration Canada. (1996). Canadian language benchmarks: English as a second language for adults/English as a second language for literacy learners. Working Document. Ottawa ON: Minister of Supply and Services Canada.

Crandall, J.A., \& Pharness, G. (1991). Whole language approaches in adult literacy. In Launching the literacy decade: Awareness into action (pp. 142-151). Alberta, CA: International Reading Association/Multiculturalism and Citizenship Bureau. (ERIC Document Reproduction Service No. ED 348 890)

Curran, C.A. (1972). Counseling-learning: A whole person model for education. New York: Grune and Stratton.

Doolittle, P.E. (1995). Understanding cooperative learning through Vygotsky's zone of proximal development. Paper presented at the Lilly National Conference on Excellence in College Teaching, Columbia, SC. (ERIC Document Reproduction Service No. 384 575)

Ely, C. (1986). An analysis of discomfort, risktaking, sociability, and motivation in the L2 classroom. Language Learning, 36, 1-25.

Freeman, D., \& Freeman, Y. (1988, March). Whole language content lessons for ESL students. Paper presented at the 22nd annual meeting of the Teachers of English to Speakers of Other Languages, Chicago, IL. (ERIC Document Reproduction Service No. ED 295 468)

Gardner, R.C., \& MacIntyre, P.D. (1991). An instrumental motivation in language study: Who says it isn't effective? Studies in Second Language Acquisition, 13, 57-72.

Gattegno, C. (1972). Teaching foreign languages in schools: The Silent Way. New York: Educational Solutions. 
Hendricks, B. (1994). Improving evaluation in experiential education. ERIC Digest [Electronic version] Charleston, WV: ERIC Clearinghouse on Rural Education and Small Schools. (ERIC Document Reproduction Service No. ED 376 998)

Hussin, S., Nooreiny, M., \& D'Cruz, J.V. (2000). Sustaining an interest in learning English and increasing motivation to learn English: An enrichment program. Internet TESL Journal. Retrieved June 19, 2001, from http:/ / www.iteslj.org/Techniques/Hussin-Motivation

Janeway, A. (1977). Beyond experience: The experiential approach to cross-cultural education. In D. Batchelder \& E.G. Warner (Eds.), Beyond experience: The experiential approach to cross-cultural education. Brattleboro VT: Experiment Press.

Karsenti, T. (2001). La motivation de l'élève bilingue à apprendre le français en immersion: Stratégies pédagogiques exemplaires d'enseignants du primaire. Retrieved July 6, 2001, from University of New Brunswick:http://www.unb.ca/slec/Events/Actes/Karsenti.html

Koenderman, M. (2000). Monitor training manual. Unpublished document. Sherbrooke, QC: English Language Summer School, Université de Sherbrooke.

Kolb, D. (1984). Experiential learning: Experience as the source of learning and development. Englewood Cliffs, NJ: Prentice-Hall.

Kolb, D., Kowal, M., \& Swain, M. (1994). Using collaborative language production tasks to promote students' language awareness. Language Awareness, 3(2), 73-91.

Krashen, S.D. (1985). The input hypothesis: Issues and implications. London: Longman.

Lozanov, G. (1978). Suggestology and outlines of suggestopedy (M. Hall-Pozharlieva \& K. Pashmakoy, Trans.). New York: Gordon and Breach Science Publishers.

Lewis, C.C., Moss, D., \& Van Duzer, C. (1998). Project-based learning for adult English language learners. ERIC Digest: National Center for ESL Literacy Education. Retrieved September 13, 2000 from http:/ / www.cal.org/ncle/digests/ProjBase.htm

Nunan, D. (1995). Closing the gap between learning and instruction. TESOL Quarterly, 29, 133-157.

Oxford, R.L., \& Scarcella, R. (1992). The tapestry of language learning: The individual in the communicative classroom. Boston, MA: Heinle \& Heinle.

Oxford, R.L., \& Shearin, J. (1996). Language learning motivation in a new key. In R.L. Oxford (Ed.), Language learning motivation: Pathways to the new century. Honolulu, HI: University of Hawaii, Second Language Teaching and Curriculum Center.

Padgett, G.S. (1994). An experiential approach: Field trips, book publication, video production. TESOL Journal 3, 8-11.

Parks, S. (2000). Same task, different activities: Issues of investment, identity, and use of strategy. TESL Canada Journal 17(2), 64-88.

Rigg, P. (1991). Whole language in TESOL. TESOL Quarterly, 25, 521-547.

Rogers, C. (1969). Freedom to Learn. Columbus, OH: Charles E. Merrill.

Saddington, T. (2001). Experiential learning. Retrieved July 15, 2001 from

http://www.el.uct.ac.za,

Spruck-Wrigley, H. (1998). Knowledge in action: The promise of project-based learning. Focus on Basics, 2(1-4), 13-18.

Stern, H.H. (1990). Analysis and experience as variable in second language pedagogy. In B. Harley, P. Allen, J. Cummins, \& M. Swain (Eds.), The development of second language proficiency (pp. 93-109). Cambridge, UK: Cambridge University Press.

Tremblay, R., Duplantie, D., Huot, D. (1990). The Communicative/experiential syllabus. Ottawa: Raymond Leblanc.

Vygotsky, L.S. (1978). Mind in society, The development of higher psychological processes. Cambridge, MA: Harvard University Press.

Wallerstein, N. (1983). Who are the students? Language and culture in conflict. Reading, MA: Addison-Wesley.

Wajnryb, R. (1990). Grammar dictation. Oxford, UK: Oxford University Press.

Wilhelm, K.H. (1999). Collaborative dos and don'ts. TESOL Journal, 8, 14-19. 